\begin{tabular}{|c|c|c|c|}
\hline$\underbrace{\text { INTERNATIONAL }}_{\text {INESEG }}$ & $\begin{array}{r}\text { International } \\
\text { Res } \\
w w v\end{array}$ & $\begin{array}{l}\text { urnal of Health Services } \\
\text { rch and Policy } \\
\text { rgipark.org.tr/ijhsrp }\end{array}$ & \\
\hline $\begin{array}{c}\text { SCIENCE AND } \\
\text { EDUCATION GROUP }\end{array}$ & e-ISSN: 2602-3482 & DOI:10.23884/ijhsrp.2019.4.3.02 & IJHSRP \\
\hline
\end{tabular}

\title{
DETERMINATION OF OCCUPATIONAL COMPUTER USAGE LEVELS OF NURSES IN MEDICAL INSTITUTIONS: A REAL HOSPITAL CASE STUDY
}

\author{
Alaattin Parlakkılıç ID $^{\text {iD }}$ \\ ${ }^{1}$ Department of Management Information Systems, Ufuk University, Turkey \\ *Corresponding author; aparlakklc@gmail.com
}

\begin{abstract}
With the development of technology, the role and responsibility of nurses in various health institutions have changed. The main purpose of this change is to provide better quality health services to individuals. This research aims to investigate the Information Technology Readiness of Public Health Nurses in Turkey. A survey was done with a total of 104 nurses. To measure IT readiness, technological skills readiness, attitude readiness, task-ready information technology readiness and institutional support readiness were evaluated using a five-point Likert scale. The scores of the participants were evaluated as technological skills readiness was 3.83 (76,6\%); attitude readiness was 3.67 (73,4\%), task-ready information technology readiness was 3.85 (77\%) and institutional support readiness was $3.65(73 \%)$. The results of the dimensions show that nurses are extremely prone to use technology in their work. The overall results show that the information technology readiness for nurses has been found at 3.75 (75\%) and needs a few improvements.
\end{abstract}

Keywords: Information technology readiness, technological skills, attitude, task-ready, institutional support

Received: July 20, 2019

Accepted: November 26, 2019

\section{Introduction}

Information Technology (IT) has affected the delivery of healthcare services and gives ways to use health applications among health services providers and patients Health Information Technology platforms are specifically targeted at assisting individuals and wellness management. Information Technology reaches more than $90 \%$ of the world's population [1].

Nurses can improve patient health and minimize the need for office visits for the routine management of some of the acute and chronic issues by using IT tools. Nurses can track patients proactively by text message, e-mail, telephone call, and, if significant enough, an office visit [2].

Information technology is expected that nurses take an active role within health institutions and bring solutions to the problems that arise [3]. In the health system, quality and timely information are of great importance. In this case, computer systems and technology are of vital importance in the developing health system [1].

The current situation of IT in medical support can promise nurses to manage and support healthcare problems to solve. With the development and availability of smart and mobile devices, uninterrupted access to information technologies is possible. Information technologies and new communication facilities are used in healthcare services as well as in the research and training of staff in this field [4]. 
This study aims to reveal the information technology readiness levels of nurses and to investigate the effects on nurses. For this aim, the following sub-objectives will be sought to determine the nurses' information technology readiness levels and its effects:

1. What are the levels of technological skills readiness, attitude readiness, task-ready readiness and institutional readiness of nurses?

2. What is the relationship between the dimensions of information technology readiness of nurses?

3. What is predictive for IT readiness for nurses?

4. What is the overall level of information technology readiness of nurses?

\section{Information Technology in Healthcare}

Health Information technology has a variety of objectives such as improving medication adherence or helping patients gain control of chronic conditions regardless of the problems trying to solve or condition. Health Information technologies may have any of the following functions or they may combine them to achieve the desired result. Functions of Health Information Technologies can be stated as follows [5]:

- Inform

- Advise

- Communicate

- Measure

- Monitor

- Motivate.

In nursing, information technologies and nurses' knowledge about patient care are synthesized more easily. First of all, the knowledge and skills of basic information technologies are needed. As a result, there will be a significant increase in the knowledge and proficiency levels of nurses if they have competency in IT. Information technologies are used in nursing for the following purposes [3]:

- Record nursing practices,

- Registration of products used in nursing services,

- Researches,

- Care and treatment of individuals,

- Providing educational activities to health workers,

Nursing practices in light of current information and computer usage are important. Nurses should have sufficient information and skills at a desirable quality. Nursing activities about patients during their taskbased jobs can be mentioned as follows [24]:

- Patients Training of patients,

- Creating a program for patient care,

- Planning the delivery time of drugs,

- Record the requests of physicians,

- Obtaining medicines from a pharmacy.

Through integrating, patient-reported outcomes or results of passive data collection Health Information technologies may provide data visualization allowing both patients and nurses can monitor a patient's condition, track progress over time and seek to motivate patients to make better health 
decisions. This can be done with messages that reach patients at the right time, such as when they need to take their medication [6].

Most Health Information technologies consist of three generic functions which are delivery, promotion and monitoring and evaluation. Delivery provides to conduct diagnosis and provide care with maintaining timeliness and tracking. Promotion creates awareness among patients and helps to adopt healthy behaviors. In health promotion, appropriate healthy practices and assistances help towards the aimed behavioral goals [7].

Monitoring and evaluation improve the delivery and promotion actions in health. In the monitoring data, collection and analyses are the main efforts for the information system. Nurse experts agree it's important for nurses to get involved in the development of Health Information tools that support patients as well as themselves in their clinical practice. So, to empower lifestyle management through the use of Health Information tools, nurses must understand both the potential and limitations of technologies for helping patients to manage a healthy lifestyle [8].

Smartphones and wearable activity trackers and Web-based applications can be used to improve patient care and empower families in the process. Health Information technology has areas of focus include:

- Improving patient compliance

- Disseminating health information among the community

- Remote diagnosis and support for on-the-ground health care workers

- Health data entry and disease surveillance

- Emergency Response [9].

When considering mobile Technologies, global coverage and device technology support require the selection of any device or service for ensured data security, integrity, quality, and privacy. The right Health technology for needs generally depends on evaluating the following criteria:

- Type and purpose of data to be collected

- Quality and frequency of data collection needed to meet study goals

- Reliability, maturity, and capability of the technology

- Regulations and guidance

- Participant compliance and scope of device capabilities

- Study populations

- Geographies where data collection will take place

- Budget, timelines, and support

- Technological skills readiness [10].

Health Information technologies have obstacles when implementation and utilization take place which include:

- Establishing hospital administrator support;

- Overcoming staff resistance to change;

- Training to different learning styles and comfort levels with technology;

- Securing patient confidentiality;

- Cost of infrastructure and maintaining consistent internet access;

- Failure or malfunction of handheld devices; and

- Ensuring that mobile devices are not a distraction in the workplace [9]. 
When we look at the Health Information technology studies which have been done until now, especially smartphone and its functionalities have been extensively used. In this context, a survey done in 2015 by InCrowd, showed that $95 \%$ of nurses own a smartphone and $88 \%$ of them use smartphone apps at work. A total of 73 percent of polled nurses use smartphones to access clinical data particularly information on drug interactions. Also, 72 percent of survey takers use mobile health apps to learn about medical conditions and disorders In February 2014, Wolters Kluwer's survey revealed that nurses' use of smartphones was $67 \%$ and medical residents by $80 \%$. Also in mHealth App Developer Economics 2014 report, fitness, medical reference, and wellness apps made up the largest categories [11]. A recent U.S. Department of Education report provides subject vocabulary and disciss an explicit comprehension strategy of IT for health motivation [12].

\section{Readiness}

Readiness is a concept defined differently in the literature. This includes psychological and physiological concepts that the individual needs to show certain behavioral competencies. Institutional changes are included in organizational development activities. The effectiveness and success of these changes depend on many factors. Readiness to change is one of the most important of these factors [2].

Holt and Vardaman [13] reported that conceptual readiness for change is composed of both individual differences and structural elements. The readiness reflects the level of acceptance and adoption of a change plan for the change of a certain status quo by the organization and its members. These writers refer to the readiness to change declares "Let's think of an organization that is full of enthusiastic and energetic individuals for a new initiative, but not in terms of equipment. It is not possible to say that this organization is more prepared than an organization consisting of full but unwilling individuals. For this reason, we argue that the elements of individual and structural differences should be taken into consideration" [13].

The readiness to change is a factor that has a significant impact on the attitude of the employees towards change implementation and thus on the success measure of this initiative. A study on nurses reveals that nurses are positive in the use of computers in the field of health. According to this, the individual characteristics of the nurses are effective in the degree of computer use [14].

IT readiness provides information for the specific needs of learning. All aspects of learning including students, lecturers, technology and the environment must be ready before implementation [15].

This study explores four dimensions to measure IT readiness that has been identified by investigating previous researches. So, information technology readiness has been examined in four dimensions as technological skills readiness, attitude readiness, task-ready information technology readiness and institutional support readiness. These dimensions are defined as follows:

Technological Skills Readiness: The concept of technical skill readiness usually focuses on the learning of technological infrastructures. Technological readiness refers to the observable and measurable technical competencies [16].

Attitude Readiness: The concept of attitude readiness is closely related to concepts such as trust, risk control, concern, and satisfaction. The responses of individuals to change can vary. Sometimes individuals adopt changes quickly and sometimes take a long time to absorb these changes [17].

Task-ready Information Technology Readiness: Information technology readiness for the task is the ability of individuals to work with high efficiency from business life depends on their ability to 
benefit from these technological tools. The requirements in working life increase: more knowledge is necessary as well as flexibility referring to a fast familiarization with new working environments [18].

Institutional Support Readiness: The corporate support readiness can be listed as superiors' support, peer support, and positive organizational atmosphere [19]. People can work more easily in business environments where receive support. Readiness refers to whether a learner/trainee or an institution is financially ready for an e-learning program [12]. Institutional Support considerations of implementing within organizations seem to take a central place within the existing literature.

\section{Methods}

\subsection{Study design}

This study employed a survey to examine the occupational computer usage level of the nurses working at Ufuk University Hospital in Ankara. The total number of nurses in the hospital is 160 . The questionnaires were distributed to all nurses, but 104 nurses returned the survey. The research method is cross-sectional and descriptive. In the first part, there were questions to determine the demographic information of the participants. The second part was used to identify the information technology readiness of the participants.

The questionnaire consisted of 5 sizes of Likert type ( $1=$ strongly disagree, $2=$ Disagree, $3=$ Undecided, 4 = Agree 5 = strongly agree). The dimensions have been as technological skills readiness, attitude readiness, task-ready information technology readiness and institutional support readiness in the survey.

The findings of the demographic information of the participants were firstly analyzed by the frequency analysis method. Then, for each readiness dimension, the mean and the mean values of the items were calculated. It was seen that the variables were consistent with the normal distribution by looking at the skewness and kurtosis values. The skewness value (Skewness) is within \pm 1 limits, and the kurtosis value (Kurtosis) is within \pm 2 boundaries. Therefore, parametric tests used in the analysis. Pearson correlation analysis was used to determine the relationships between readiness dimensions. Then, the readiness dimensions were analyzed with independent sample t-test and one-way ANOVA.

As the question items for the questionnaire dimensions are at a 5-point Likert type, it is assumed that the participants who score 3.40 and above for the scoring are expected to be at the expected readiness level [17].

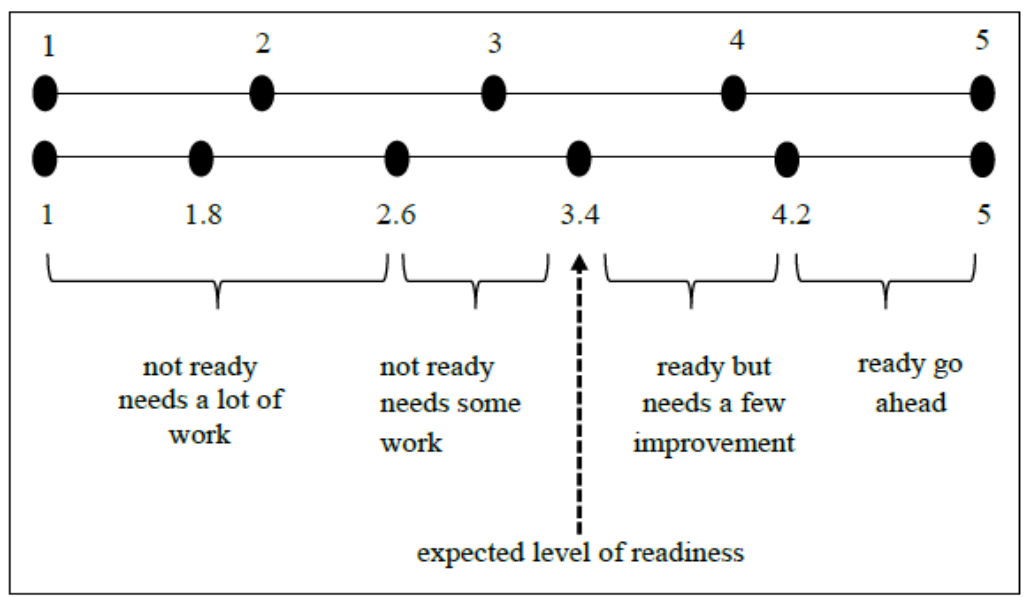

Figure 1. Evaluation Criteria for Readiness 


\section{Results}

\subsection{Demographic Information}

The survey was administered to the 104 nurses. The details of demographics are as shown in Table1.

Table 1. Frequency Analysis Results of Demographic Information

\begin{tabular}{|l|c|c|}
\hline & Frequency & Percent \\
\hline Gender & & \\
\hline Female & 80 & 76,9 \\
\hline Male & 24 & 23,1 \\
\hline Age & & \\
\hline 25 years and under & 41 & 39,4 \\
\hline Between 26-30 years & 22 & 21,2 \\
\hline 36 years and older & 27 & 26,0 \\
\hline Education status & 13 & 12,5 \\
\hline Graduate or graduate degree & & \\
\hline High School, Associate Degree or Certified & 30 & 34,6 \\
\hline Marital status & 70 & 63,4 \\
\hline Married & 39 & \\
\hline Single & 65 & 62,5 \\
\hline Information technology access & & \\
\hline Internet connection at home & 72 & 70,6 \\
\hline Workplace & 56 & 54,9 \\
\hline Mobile phone / tablet / PDA & 87 & 85,3 \\
\hline Wi-Fi HotSpots & 7 & 6,9 \\
\hline Internet cafe & 2 & 2,0 \\
\hline School / university & 4 & 3,9 \\
\hline & & \\
\hline
\end{tabular}

Gender: As a result of the independent sample t-test, technological skills, attitude readiness, information technology readiness for the task and institutional support readiness did not differ according to the gender of the participants and are respectively shown in Table2.

Age: As a result of the one-way analysis of variance, it has been found that organizational support readiness does not differ significantly from the participants' age, F $(3,99), \mathrm{p}>, 05$. On the other hand, technological skills, attitude readiness, and information technology readiness for the task differed significantly from participants' readiness, according to the age of participants and are respectively shown in Table2.

Bonferroni Post-hoc analysis was performed to determine the significant differences among the groups. Accordingly, it was found that the technological skills and attitude readiness of the participants under the age of 25 were significantly higher than the participants over the age of 36 years. Also, it was found that participants in the age group 25 were significantly more likely to have information technology readiness for the task than the participants aged 26 to 30 years. 
Education level: As a result of the independent sample t-test, it has been found that technological skills, attitude readiness, information technology readiness for the task and institutional support readiness do not differ significantly according to the education level of the participants and are respectively shown in Table2.

Marital status: As a result of the independent sample t-test, it was found that technological skills, attitude readiness, task-oriented information technology readiness and institutional support readiness did not differ significantly according to the marital status of the participants, respectively and are respectively shown in Table2.

Table2. Results of Demographic Information with respect to IT Readiness Dimensions

\begin{tabular}{|c|c|c|c|c|c|c|c|c|}
\hline & \multicolumn{2}{|c|}{$\frac{\bar{d}}{\tilde{D}}$} & \multicolumn{2}{|c|}{$\underset{<}{\infty}$} & \multicolumn{2}{|c|}{.气 } & \multicolumn{2}{|c|}{ 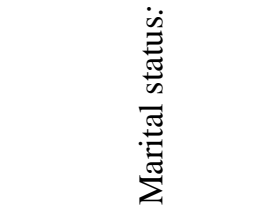 } \\
\hline & $\mathrm{t}$ & $\mathrm{P}$ & $\mathrm{F}$ & $\mathrm{p}$ & $t$ & $P$ & $t$ & $P$ \\
\hline $\begin{array}{l}\text { Technological } \\
\text { Skills readiness }\end{array}$ & $-0,961$ & $>, 05$ & 4,887 & $\mathrm{p}<, 05$ & 1,883 & $p>, 05$ & $-0,367$ & $p>, 05$ \\
\hline $\begin{array}{l}\text { Attitude } \\
\text { readiness }\end{array}$ & 0,294 & $>, 05$ & 3,512 & $\mathrm{p}<, 05$ & $-1,087$ & $\mathrm{p}>, 05$ & $\stackrel{,^{-}}{1,951}$ & $\mathrm{p}>, 05$ \\
\hline $\begin{array}{l}\text { Task-ready } \\
\text { information } \\
\text { technology } \\
\text { readiness }\end{array}$ & 0,373 & $>, 05$ & 2,824 & $\mathrm{p}<, 05$ & $-0,772$ & $\mathrm{p}>, 05$ & 0,560 & $\mathrm{p}>, 05$ \\
\hline $\begin{array}{l}\text { Institutional } \\
\text { support readiness }\end{array}$ & 0,818 & $>, 05$ & 2,199 & $\mathrm{p}>, 0$. & $-0,775$ & $\mathrm{p}>, 05$ & 0,66 & $p>, 05$ \\
\hline
\end{tabular}

Internet Access: When the participants' access to the Internet was examined, it was seen that $85.3 \%$ of them provided internet access via personal mobile devices. It is not surprising that these people in the full-time workforce provide internet access with more mobile devices. They use the internet connection in their homes by $70.6 \%$. And $54.9 \%$ of them use the connection provided by the workplace, $6.9 \%$ of them use wi-fi hotspots, $3.9 \%$ of them use the internet and $2 \%$ of them use internet café.

\subsection{Readiness Dimensions}

The quantitative data analysis addresses the level of readiness for nurses in each dimension and identifies critical factors that need to be considered to determine a successful IT for the e-learning level. The level of readiness in each dimension was assessed individually. Readiness Dimensions Levels are shown in Table 3.

Table.3 Readiness Dimensions Levels

\begin{tabular}{|l|l|}
\hline Readiness Dimensions & \multicolumn{1}{|c|}{ Readiness Level(\%) } \\
\hline Technological skills & 76,6 \\
\hline Attitude readiness & 73,4 \\
\hline $\begin{array}{l}\text { Task-ready information } \\
\text { technology }\end{array}$ & 77 \\
\hline Institutional support & 73 \\
\hline
\end{tabular}


Technological skills readiness dimension: When the results of the descriptive analysis of technological skill dimensions and items were examined, it was seen that the participants have an average score of $3.83(76,6 \%)$. This score indicates that the participants were skilled in technology and mostly use mobile devices.

Attitude readiness dimension: When the results were examined, it was seen that the participants have an average score of $3.67(73,4 \%)$. In other words, the attitudes of the participants towards information technologies are positive. Most participants are aware of the usefulness of information technologies in professional life and use them.

Task-ready information technology readiness: When the results of task-ready information technology readiness were analyzed, it was seen that nurses have a score of 3.85 (77\%). It can be seen that participants are quite open to new technologies.

Institutional support readiness dimension: When the results were examined, it was seen that the participants have an average score of $3.65(73 \%)$. This means that the participants expect support from their institutions.

\subsection{Relationship Between Dimensions}

When the Pearson correlation analysis results were examined to determine the relationships between the dimensions, the following results were found (Table4):

Table 4. Results of Pearson Correlation Analysis for Relationships Between Dimensions

\begin{tabular}{|c|c|c|c|c|}
\hline & 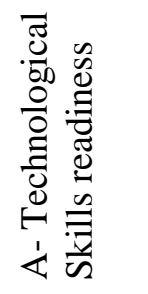 & 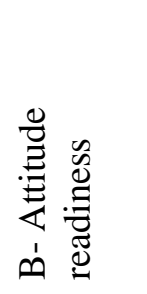 & 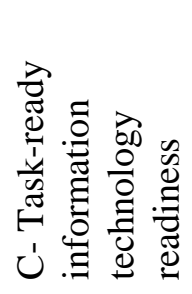 & 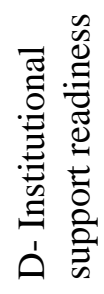 \\
\hline \multicolumn{5}{|l|}{ A- Technological Skills readiness } \\
\hline B- Attitude readiness & ,359* & & & \\
\hline $\begin{array}{l}\text { C-Task-ready information } \\
\text { technology readiness }\end{array}$ &, $510 *$ &, $556^{*}$ & & \\
\hline D- Institutional support readiness &, 110 & ,350* &, $461 *$ & \\
\hline
\end{tabular}

$* \mathrm{p}<, 01$

- There is a significant and positive correlation between the dimensions of technological skills and attitude readiness, task-ready information technology readiness dimensions $(r=359, \mathrm{p}<$, 01). Thus, when the technological skill increases, attitude readiness, and task-ready information technology readiness increase.

- On the other hand, no significant correlation was found between the technological skill dimension and institutional support readiness $(\mathrm{r}=, 110, \mathrm{p}>, 05)$.

- There is a significant and positive correlation between the attitudes readiness, task-ready information technology readiness and institutional support readiness, respectively $(r=, 556$, 
$350, \mathrm{p}<, 01)$. Accordingly, when the readiness of the altitude increases, it can be said that the task-ready information technology readiness and the institutional support readiness increase.

- There is a significant and positive correlation between the institutional support readiness and the task-ready information technology readiness $(\mathrm{r}=, 461, \mathrm{p}<, 01)$. Accordingly, it can be said that when the task-ready information technology readiness increases the institutional support readiness increases.

\section{Discussion}

\subsection{Demographic Information Evaluation}

In this study, the relationships between the demographic information of the participants and the readiness of information technologies were examined. When the participants' access to the Internet was examined, it was seen nurses use computers and mobile devices (smartphones, tablets, laptops) without problems when connecting to the internet. Therefore, the fact that the mobile technology trend shown here can be reflected in the works will bring great benefits [20].

When the demographics were participants in the 25-year age group had significantly higher technological skills and attitude readiness. But Cakir and Horzum [21], who investigated that online learning was not affected by the participant age. Indeed, this finding is not supported by most studies. Pillay et al.in their study found that participants over the age of 40 have technical competence in online learning was significantly lower than in other participants [22]. This judgment is consistent with the finding that those over the age of 36 show lower information technology readiness. However, it can be seen in the literature that technical competence and computer adequacy are rather low in individuals older than 40 years, rather than a linear decrease with age. Fogerson [23] stated that online learning readiness increased with age. Therefore, individuals who are mentally mature and have knowledge accumulate are more inclined to use information technologies. However, individuals over 40 years of age do not have sufficient skills in general.

When the educational status is considered, it is seen that the level of the education level of the participant does not affect any information technology readiness dimension. However, it can be said that this data is not meaningful if it is taken into account that the participants of the study are not persons with lower education levels. However, it was found that undergraduate or associate degree did not make any difference in this context.

According to the independent sample t-test results, the marital status, which is the last demographic characteristic examined, does not affect any of the information technology readiness dimensions.

\subsection{Readiness Dimensions}

In the study, information technology readiness was examined in four different dimensions: technological skills, attitude readiness, information technology preparedness for the task and readiness of institutional support. When the relations between these dimensions are examined, it is seen that there are positive correlations between technical skills and attitude readiness and teask-ready information technology readiness for the job. Accordingly, when the technological skills readiness of the participants' increases, attitudes and attitudes towards the task are increasing. Also, there is a positive correlation between attitude readiness and teask-ready information technology readiness for the task and the readiness for institutional support. Accordingly, when the readiness of the participants increased, 
task-ready information technology readiness and institutional support readiness increased. Finally, a positive correlation was found between the readiness of task-ready information technology readiness and institutional support readiness. Accordingly, it can be said that when the readiness of task-ready information technologies increased, the institutional support readiness increased. When the average scores of the participants' four dimensions were examined, it was found that these scores were above the expected readiness limit (3.40) determined by Aydın and Taşc1 [17] and therefore the information technology readiness of the participants was high. The level of technological skills readiness was 3.83 $(76,6 \%)$ and ready but needs a few improvements for readiness. The level of attitude readiness was $3.67(73,4 \%)$ and ready but needs a few improvements for readiness. The level of task-ready information technology readiness nurses was ready at $3.85(77 \%)$ and ready but needs a few improvements for readiness. The institutional support readiness was $3.65(73 \%)$ indicating ready but needs a few improvements for readiness. When the information technology readiness was analyzed totally, it was seen that there has been a significant and positive correlation among readiness dimensions.

\section{Conclusion}

With this study, four dimensions of IT readiness were identified to measure readiness that had been derived from the literature review. These dimensions were categorized as technological skills readiness, attitude readiness, task-ready information technology readiness and institutional support readiness to determine the IT readiness level of nurses. According to the results, it was seen that the participants' information technology readiness did not differ significantly according to their gender, educational status, and marital status. On the other hand, it was found that the technological skills and attitude readiness of the participants under the age of 25 were significantly higher than the participants over the age of 36 years. According to the results, the average value of the information technology readiness is $3.75(75 \%)$ and the nurses can reach a much better level with less personal effort and needs a few improvements for readiness.

\section{References}

[1] Eley R, Fallon T, Soar J, Buikstra E, Hegney D. "The Status of Training and Education in Information and Computer Technology of Australian Nurses: A National Survey", Journal of Clinical Nursing, 17(20), 2758-2767, 2008.

[2] Sinsky, C. A., Willard-Grace, R., Schutzbank, A. M., Sinsky, T. A., Margolius, D., Bodenheimer, T. "In search of joy in practice: A report of 23 high-functioning primary care practices", Annals of Family Medicine, 11(3), 272-278. http://dx.doi.org/10.1370/afm.1531, 2013.

[3] Kaya, N., Aştı, T. "Sağlık Bakımında Bilgisayar Kullanımına Yönelik Tutum Ölçeğinin Güvenirlik ve Geçerliği”, İstanbul Üniversitesi Florence Nightingale Hemşirelik Yüksekokulu Dergisi., 16(61), 24-32, 2008.

[4] Jaeger, F. N., Bechir, M., Harouna, M., Moto, D. D., Utzinger, J. "Challenges and opportunities for healthcare workers in a rural district of Chad", BMC health services research, 18(1), 7. doi:10.1186/s12913-017-2799-6C, 2018.

[5] Free, C., Phillips, G., Galli, L., Watson, L., Felix, L., Edwards, P., Haines, A. “The effectiveness of mobile-health technology-based health behaviour change or disease management interventions for health care consumers: a systematic review", PLoS medicine, 10(1), e1001362. doi:10.1371/journal.pmed.1001362, 2013.

[6] Bowles, K. H., Dykes, P., Demiris, G. "The use of health information technology to improve care and outcomes for older adults", Research In Gerontological Nursing, 8(1), 5-10. doi:10.3928/19404921-20121222-01, 2015. 
[7] Matthew-Maich, N., Harris, L., Ploeg, J., Markle-Reid, M., Valaitis, R., Ibrahim, S.,Isaacs, S. "Designing, Implementing, and Evaluating Mobile Health Technologies for Managing Chronic Conditions in Older Adults: A Scoping Review", JMIR mHealth and uHealth, 4(2), e29. doi:10.2196/mhealth.5127, 2016.

[8] Janice, P.L On the move with mHealth: Nurses develop mobile health tools. https://www.nurse.com/blog/2015/11/09/on-the-move-with-mhealth-nurses-develop-mobilehealth-tools/

[9] Austin. R., Hull, S. "The Power of Mobile Health Technologies and Prescribing Apps", CIN: Computers, Informatics, and Nursing, 32(11). 513-515, 2014.

[10] Cobb, C., Sudar, S., Reiter, N., Anderson, R., Roesner, F., Kohno, T. Computer." Computer security for data collection technologies", Conference on Information and Communication Technologies and Development, 2016.

[11] Farmer, R. "The Rise of Mobile Health Apps, Minority and Community Health, Nurse Health. 2015

[12] S. F. Ellen, P. H. Pixita, and E. M. Susan, "Collaborating to Cross the Mathematics-Literacy Divide: An Annotated Bibliography of Literacy Strategies for Mathematics Classrooms", Journal of Adolescent\& Adult Literacy, 55 (1): 57-66, 2011.

[13] Holt, D. T, Vardaman, J. M. "Toward a comprehensive understanding of readiness for change: The case for an expanded conceptualization”, Journal of Change Management,13(1), 9-18. http://dx.doi.org/10.1080/14697017.2013.768426 ICTD '16. ACM, New York, NY, USA. 2:12:11, 2013.

[14] Kaya, N. "Factors Affecting Nurses' Attitudes Toward Computers in Healthcare", Computers Informatics Nursing. 29(2), 121-129, 2011.

[15] Nyoni, J. "E-readiness of Open and Distance Learning (ODL) Facilitators: Implications for Effective Mediation", Perspectives in Education, 32(3), 78-91, 2014.

[16] Saekow, A., Samson, D. "E-learning Readiness of Thailand's Universities Comparing to the USA's Cases", International Journal of e-Education, e-Business, e-Management and eLearning, 1(2): 126-131, 2011.

[17] Aydın, C. H., Taşçı. D. "Measuring Readiness for e-Learning: Reflections from an Emerging Country", Educational Technology \& Society, 8(4), 244-257, 2005.

[18] Caison, A.L., Bulman D., Pai S., Neville, D. "Exploring the technology readiness of nursing and medical students at a Canadian University", Journal of Interprofessional Care, 22(3): 283294,2008 .

[19] Joo, Y. J., Joung S., Sim W. J. "Structural relationships among internal locus of control, institutional support, flow, and learner persistence in cyber universities", Computers in Human Behavior, 27(2), 714-722, 2011.

[20] Şahin, G., Başak, T.” Mobile Learning in Nursing "M-Learning", Journal of Human Sciences, 14(3), 2017.

[21] Çakır, Ö., Horzum, M. B. “Öğretmen Adaylarının Çevrimiçi Öğrenmeye Hazır Bulunuşluk Düzeylerinin Çeşitli Değişkenler Açısından İncelenmesi”, Eğitimde Kuram ve Uygulama. 11(1), 1-15, 2015.

[22] Pillay, H., Irving, K., Tones, M. "Validation of the Diagnostic Tool for AssessingTertiary Students' Readiness for Online Learning”, Higher Education Research \& Development, (2), 217-234,26, 2007.

[23] Fogerson, D. L. "Readiness Factors Contributing to Participant Satisfaction in Online Higher Education Courses", Doctoral Dissertations, Knoxville: University of Tennessee, 2005.

[24] Kaya H, Iş1k B, Bodur G. "The relationship between in-service training nurses' attitudes toward computer in health care and computer anxiety in Turkey", International Journal of Human Sciences. 11(2):948- 963, 2014. 